\title{
Assessing the Value and Impact of Digital Content
}

\section{Brinley Franklin}

University of Connecticut, brinley.franklin@uconn.edu

Terry Plum

Simmons College, terry.plum@simmons.edu

Follow this and additional works at: https://opencommons.uconn.edu/libr_pubs

Part of the Library and Information Science Commons

\section{Recommended Citation}

Franklin, Brinley and Plum, Terry, "Assessing the Value and Impact of Digital Content" (2008). Published Works. 17. https://opencommons.uconn.edu/libr_pubs/17 


\title{
Assessing the Value and Impact of Digital Content
}

\author{
Brinley Franklin and Terry Plum
}

Digital content affords librarians the ability to understand networked services usage in a way that was not previously possible in the traditional print library environment. As library users have responded favorably to the rapid growth of available digital content during the last decade, a number of assessment initiatives emerged that improve our knowledge of how library resources are actually being used.

In the print environment, online public access catalogs provided only limited management information about circulating materials. In-house library collections usage statistics were unreliable. Journal use surveys, based on self-reported checklists or reshelving counts, were unconvincing. In truth, librarians never completely understood how print collections were used. The digital content environment affords libraries unprecedented opportunities to measure, assess, and analyze networked services use.

Projects are now underway to standardize measures of digital content use and to assess its value, including: user satisfaction with networked resources, cost/benefit ratios, return on investments, and determinations of how specific user populations apply digital content to their work, based on demographic and purpose of use analyses. Electronic services use data is being collected not only for collections management decisions, but to justify increased funding for digital content, to craft library services in new ways, to inform management decisions, and to assert the impact of networked electronic resources and services on teaching, learning, and research. 


\section{Traditional Print Collection Use in Those "Miles of Aisles"}

About a decade into the digital information environment, we already know considerably more about digital content use than we ever did about print journal and book use. In previous decades, librarians conscientiously counted outputs including circulating library materials, reference and information questions, and interlibrary loans although the data collected, in retrospect, was unreliable and, most likely, inconsistent, due to varying loan periods, local practices regarding how to count informational and directional versus reference questions, and variances in how libraries classified interlibrary loans as opposed to circulation transactions. Journal review projects were transparently aimed at cancelling titles and were subject to manipulation.

Librarians collected usage data, when they were: (a) interested in measuring their libraries' performance, (b) asked to compile statistics for professional associations or governmental agencies, or (c) confronted with budget cuts. They typically relied on gross circulation counts and routinely employed unscientific and unreliable sampling plans and primitive in-house data collection methods such as asking users not to re-shelve library materials so the library could count them. These "usage studies" purported to

measure library collections use when in fact there was never any tangible proof or consistent interpretation of what a book being removed from the shelf, or even a circulating item, really represented. 
It is telling that the authors of one of the most commonly cited articles on print collection use in an academic library, published in 1977 and aptly titled, "Use of a University Library Collection" observed that:

...the gross data available up to this point have been too global in character and too imprecise in nature to serve as an adequate basis for the reformulation of acquisitions policies. It is not particularly helpful for a bibliographer to know that ten percent of the titles selected will satisfy 90 percent of client demand for materials in a given discipline, unless we can determine which ten percent. It is useless to tell the acquisitions librarian that half the monographs ordered will never be used, unless we can specify which 50 percent to avoid buying. ${ }^{1}$

As recently as 2003, a Mellon Foundation-funded study by the Tri-College Library Consortium (Bryn Mawr, Haverford, and Swarthmore Colleges) done in conjunction with the Council on Library and Information Resources found that approximately 75 percent of the items in the three libraries' collections had circulated one or fewer times in the past ten years. Also, about 40 percent of the items in the collections overlapped (i.e., they were held on more than one campus). About half of these overlapping items had not circulated in the past 11 years. $^{2}$

In retrospect, collection development in the print environment was more of an art than a science. Libraries knew how much they were spending, but were unable to ascertain how 
their collections were being used or how to use the data they could collect to better inform purchasing decisions.

\section{The Brave New World of Digital Content, New Measures, and E-Metrics}

In January, 1999, Carla Stoffle, the Dean of Libraries at the University of Arizona and Chair of the Association of Research Libraries' (ARL) Statistics and Measurement Committee, invited members from ARL's Statistics and Measurement Committee and the ARL Management Committee to Tucson to discuss the concept of "New Measures." This retreat was in response to: (1) increased demand for libraries to demonstrate outcomes and impacts (instead of inputs and outputs) important to their institution and (2) increasing budgetary and political pressure to maximize efficient use of resources and to identify best practices. ${ }^{3}$

Ultimately, the "New Measures" initiatives that Carla Stoffle set in motion resulted in several assessment tools sponsored by ARL libraries that began to assess the new world of digital content. These included: Project SAILS (Standardized Assessment of Information Literacy Skills) in partnership with Kent State University; and electronic resources measures (E-Metrics), developed by a group of 24 sponsoring ARL libraries under a contract with Florida State University's (FSU) Information Use Management and Policy Institute and under the leadership of project co-chairs Sherrie Schmidt, Dean of Libraries at Arizona State University and Rush Miller, University Librarian at the University of Pittsburgh. As two of the Florida State University consultants, Chuck 
McClure and Jeff Wonsik Shim, reported "The proliferation of networked electronic information resources and services prompted interest and research in developing statistics and measures to describe this emerging information provision environment."

The task was not an easy one. Among the challenges documented by Sherrie Schmidt and Rush Miller were:

lack of clear and consistent definition of data elements; vendors do not "count" things in the same manner as one another; membership in a consortium can skew the statistics of the individual libraries in that consortium; libraries structure themselves differently in regard to electronic resources, making data gathering difficult; libraries do not control access to and use of important data about vendor-supplied resources; and the nature of electronic resources is changing rapidly and, therefore, data elements are shifting. ${ }^{5}$

ARL's E-Metrics project resulted in nineteen data elements representing four categories:

(1) Number of Networked Electronic Resources (2) Expenditures for Networked Electronic Resources (3) Use of Networked Electronic Resources and Services and (4) Library Digitization Activities. As described by ARL's Director of Information Services, Julia Blixrud, in 2002: 
The ARL E-Metrics project has been only a beginning, but it is a significant undertaking to identify the measures needed to provide information on the electronic resources libraries provide to their communities. The project demonstrated that the collection of data to provide that information is a complex set of activities, and requires the cooperation of many units within a library and of the vendors who produce the products and services that the libraries make available...ARL will continue to search for the best measures to determine how the provision of electronic resources contributes to the success of library users. ${ }^{6}$

The E-Metrics developed by ARL in 2002 by twenty-four of its members became ARL's Supplementary Statistics in 2003-2004. The ARL Supplementary Statistics serve as an experimental compilation to collect information on new measures. These Supplementary Statistics have yielded valuable public services and government documents' measures in the past, and currently are being used to normalize statistical measures related to electronic resources. During the next several years, some of the nineteen E-Metrics data elements developed by ARL in conjunction with FSU will most likely be deemed "mature" enough to move into the main ARL Statistics questionnaire. Others, in all likelihood, will not be determined significant enough in value or sufficiently normalized as accurate counts and will be withdrawn from consideration. ${ }^{7}$ 


\section{Vendor Supplied Data and Transaction Based Usage}

Currently, the most common approach to measuring digital content usage is based on vendor-supplied data or, less often, transaction-based usage. A number of standardssetting groups have developed guidelines for setting consistent measures of digital content usage across different publishers and products, including: Project COUNTER, or Counting Online Usage of NeTworked Electronic Resources (http://www.projectcounter.org); the International Coalition of Library Consortia, or ICOLC (http://www.library.yale.edu/consortia); the International Organization for Standardisation, or ISO, 11620 Library Performance Indicators (http://www.iso.org); and the National Information Standards Organization, or NISO, Z39.7 Library Statistics (http://ww.niso.org).

Despite Stemper and Jaguszewski's assertion in 2003 that: "vendor-supplied e-resource statistics are often unavailable, unreliable, or not comparable across vendors," ${ }^{8}$ these standardization efforts have encouraged many publishers to become COUNTERcompliant. In a complementary development, NISO is sponsoring and formalizing the work of a committee that is developing a standard, SUSHI, or the Standardized Usage Statistics Harvesting Initiative (http://www.niso.org/committees/SUSHI/) for moving Project COUNTER usage statistics into a digital repository. Adam Chandler (Cornell University) and Oliver Pesch (Ebsco Information Services) are co-chairing the committee, which according to its website, consists of "a cross-industry group of solution-seekers." 
These issues of concern to librarians and publishers related to the standardized development and interpretation of statistics surfaced at approximately the same time that electronic journals began to gain popularity. ${ }^{10}$ Libraries and particularly consortia that host electronic resources on their own servers face the same issues in collecting usage statistics as publishers and, increasingly, libraries are offering locally mounted digital collections and services whose usage they would like to effectively measure.

A useful survey of data collection related to networked resources use at the local library level can be found in White and Kamal's 2006 monograph on using e-metrics to manage and evaluate electronic resources collections. The University of Pennsylvania Library, for example, under the leadership of Joe Zucca, has created the Penn Library Data Farm, which combines locally harvested e-journal and database use with other data elements to form a library management information system. ${ }^{11}$

Stemper and Jaguszewski demonstrated in 2003 that "local use data allows us to compare usage across publishers and disciplines." They concluded that "it may be useful to occasionally compare local statistics with vendor statistics to understand usage in more depth" and "both local and vendor usage data have their own strengths and weaknesses... Both have their place in the digital library's suite of quantitative evaluation measures."12 
The increased standardization of vendor-supplied data and the development of sophisticated collection mechanisms for measuring usage by the local library or consortium will no doubt continue on mutually beneficial tracks into the foreseeable future. The development of library portal technologies such as frameworks incorporating the Joint Information Systems Committee Information Architecture Environment, or JISC IE, (http://www.ukoln.ac.uk/distributed-systems/jisc-ie/arch/) or the IMS Digital Repositories Framework (http://www.imsproject.org/digitalrepositories) and the development of library gateways ${ }^{13}$ will only encourage standardization in collecting digital content usage data from both local and remote servers.

\section{Cost-Benefit Analyses/Unit Costs, and Improved Collections Management Practices}

Galvin and Kent referred to the book budget in the academic world as "the most sacred of sacred cows" and pointed out:

The hard facts are that research libraries invest very substantial funds to purchase books and journals that are rarely, or never, called for as well as equally large sums to construct and maintain buildings designed to make accessible quickly titles that are no longer either useful to or sought by their clientele. ${ }^{14}$

Fortunately, digital content now allows us to analyze its use and determine cost-benefit analyses and unit costs and to parlay that information into more data-driven library collections management practices. 


\section{Cost-Benefit Analyses/ Unit Cost Data}

In the past, when librarians pondered the benefit of purchasing library materials against their cost, they relied on book circulation data, in-house journal use studies, or anecdotal user testimonies. Interlibrary loan requests, at least, were sometimes used to identify materials that would be more cost effective to own. Now, most libraries employ costbenefit techniques to determine whether digital content is used often enough to justify its cost. Many libraries perform this cost-benefit analysis on the basis of unit costs. ${ }^{15}$

Three ground-breaking cost-benefit analysis studies occurred between 2002 and 2004. The first, conducted at Drexel University and reported on by Carol Montgomery and Donald King, determined that, while not directly comparable, the total costs (subscription and operational) of electronic journals calculated on a cost per use basis were $\$ 1.85$ per use, compared to $\$ 17.50$ per use for print journals. These calculations were based on article views and downloads for electronic journals and four years of re-shelving counts for print journals. Electronic journal use was also much higher than the print journal use measured. ${ }^{16}$

A second study, performed by Oliver Obst at the Medical Branch Library of the University Library in Muenster, Germany in 2003, only considered subscription costs. Obst's study also determined considerably lower unit costs for electronic journal use $(€ 3.47)$ than print journal use (€18.68). Consistent with Montgomery and King's 
findings, users accessed the electronic versions of journals much more frequently than the print versions. The Muenster study also found significant differences in unit costs by publisher. ${ }^{17}$

A third study, published by the Council on Library and Information Resources in 2004, considered the non-subscription costs of current print journals, print journal back files, and electronic journals. This study was interesting in that it attempted to project cost over the estimated total life span for periodicals. Again, the authors concluded that, "other things being equal, an electronic collection should achieve lower non-subscription costs than a print collection." 18

Cost and use data is relatively easy to compile for digital resources. With most vendor supplied and transaction based usage counts, digital content usage data is based upon total usage for a given year, not a sample. Any estimates for comparable print journal usage data is usually derived from a sample. The data collected to-date indicates that the cost per use of an article in an electronic journal is fairly inexpensive. The more often that digital content is used, the lower the unit cost, and the resulting increase in perceived value to the user population reflected by increased use does not incur additional cost. Therefore, offering digital content encourages the development of library services such as marketing, instruction, and liaison outreach. Moving to digital content also nurtures the development of new technology systems to leverage already committed expenses, such as OpenURL, web usability studies, and electronic resource management systems. 


\section{Collections Management Practices}

With respect to evaluating print collection usage, Galvin and Kent, asserted that: "the available data lack sufficient predictive power to enable the librarian to modify selection

practices with assurance that the results will be more responsive to future client needs." ${ }^{19}$

Now, consortia like the Ohio Library and Information Network, or OhioLINK, (http://www.ohiolink.edu/) and the Ontario Council of University Libraries, or OCUL, (http://www.ocul.on.ca/) mount commercially licensed digital content locally and calculate cost per use data by title, by publisher, and by member library to determine which electronic resources merit continuation of their licensing and operational costs. Individual libraries measure total use of individual electronic resources and packages and calculate unit costs, usually based on vendor-supplied usage data, to decide which titles and packages have a low enough unit cost to warrant continued investment.

The University of Connecticut Networked Services Team annually calculates unit costs for electronic journals and databases and uses that information to inform collection development decisions. Unit cost analysis can help to determine whether publishers' cost increases are justified with increases in usage growing faster than the costs are inflating. While unit cost data should not be the sole 
determinant in buying decisions, it does provide data that can be used to explain to faculty and students why a title or package may not be a good investment at their university. Unit cost data also standardizes different publishers, vendors, and products so that titles and packages can be evaluated effectively.

As librarians at the University of Montana reported in 2004:

For the first time, the Collection Development Team was able to review the networked resources collection from an overview of quantitative data and relate it to the collection development policy.....At the same time, national-level initiatives to work with vendors to standardize vendor-supplied data provide the future opportunity to further expand the analysis to include how users actually use these resources once they are accessed. ${ }^{20}$

\section{Web-based Usage Surveys}

In addition to vendor supplied data and locally generated transaction usage, web-based usage surveys are increasingly relevant in the refinement of collection development and service decisions. Web-based surveys can be used to: document usage by specific user groups; determine which of the electronic services a library offers are critical to instruction/education, funded research, patient care, public service, and other institutional missions; and assess the perceived impact of digital resources and services. 
Vendor supplied data and transaction counts are typically a census of all electronic resource usage during a specific time period. Most web-based surveys are samples and require a scientific sampling plan to ensure validity and reliability. Achieving participation by a representative sample of users is important and the introduction of bias into the survey instrument and the sample must be minimized.

One way to reduce the effect of non-respondents is to survey the user as the digital resource is selected for viewing. For web-based surveys of electronic services usage which attempt to intercept the user at the point of use, inclusiveness is an important factor and the methodology for determining at what point in the session and the methods in which the survey instrument is presented to the user are critical. If a redirect to the survey is placed after one of the library's web pages and just before the user connects to the desired electronic resource or service, for example, the user who does not access the electronic resource or service through the library's web page (e.g., through a bookmark or a departmental web page) will not be included in the sample. In that case, the survey will be biased in that it is really only measuring electronic services users who access electronic services through the library's web pages.

\section{StatsQUAL ${ }^{\text {TM }}$}

Since ARL's development of E-Metrics in 2002, its focus has expanded to include three web-based survey protocols. Questions related to digital content are part of the most commonly used instrument to measure library user satisfaction, LibQUAL $+{ }^{\circledR}$, or

LibQUAL. LibQUAL $+{ }^{\circledR}$ is a gap analysis tool, administered to identify perceptions of 
service quality and gaps between desired, perceived and minimum expectations of library service. It is delivered through a remotely-hosted web site and is promoted locally through email, campus announcements, posters, and other marketing efforts to encourage participation.

A second protocol, DigiQUAL ${ }^{\mathrm{TM}}$ or DigiQUAL, measures user satisfaction with various digital libraries. It is aimed at users who are using specific, closed digital library environments, and the survey is delivered at the point of use of the digital library, rather than within the specific resources contained in that particular digital library.

A third web-based user survey methodology is MINES for Libraries ${ }^{\mathrm{TM}}$ (MINES). MINES was adopted by the Association of Research Libraries (ARL) as part of the "New Measures" toolkit in May, 2003. MINES is different from electronic resource usage measures that quantify and set digital content usage standards (e.g., ProjectCOUNTER, E-Metrics, the ICOLC Guidelines, and ISO and NISO standards) or measure how well a library makes electronic resources (LibQUAL $+{ }^{\circledR}$ ) or digital library services accessible (DigiQUAL $+{ }^{\mathrm{TM}}$ ). MINES, as currently implemented, collects demographic data about electronic resources' users, users' locations at the time of use, and their purpose of use. It is delivered at the point of use of an e-journal, database, article, digital collection, or digital library service. Collectively, LibQUAL $+{ }^{\circledR}$ DigiQUAL $^{\mathrm{TM}}$ and MINES for Libraries $^{\mathrm{TM}}$ currently comprise ARL's StatsQUAL ${ }^{\mathrm{TM}}$ product offerings. 


\section{$\operatorname{LibQUAL+}{ }^{\circledR}$}

LibQUAL has now been utilized by more than 1000 libraries worldwide and scores of articles related to LibQUAL have been published since it was adapted from the ServQUAL protocol at Texas A\&M University and then pilot tested in 2000 by twelve ARL libraries (see www.libqual.org). Early in its development, LibQUAL was a relatively complicated survey with over 50 questions. It has become simpler over the years, and now has twenty-two core items that fall into three subscales: (1) Affect of Service (2) Library as Place and (3) Information Control.

Recently, three of the primary architects of the LibQUAL phenomenon, Bruce Thompson, Colleen Cook, and Martha Kyrillidou, authored an as yet unpublished LibQUAL+ ${ }^{\circledR}$ Study titled, "Library Users' Services Desires and Tolerances: A LibQUAL+® Study.” This new study demonstrates that, of the twenty-two core items, the six most desired among the three academic library user groups (undergraduate students, graduate students, and faculty) in the United States are all part of the Information Control subscale. This finding is based on web-based survey results from more than 225,000 LibQUAL+ ${ }^{\circledR}$ participants in the United States in 2004, 2005, and 2006.

Thompson, Cook, and Kyrillidou report that the most desired core item was (1) Making electronic resources accessible from my home or office. This item ranked first among graduate students and second among undergraduate students and faculty. The second most desired core item was (2) Print and/or electronic journal collections I require for 
my work. It ranked first among faculty, second among graduate students, and fifth among undergraduates. The third most desired core item was (3) A library web site enabling me to locate information on my own. This item ranked third among faculty and undergraduate students and fourth among graduate students. ${ }^{21}$ Interestingly, all three of the most commonly identified desires are related to digital resources.

\section{DigiQUAL ${ }^{T M}$}

DigiQUAL is a collaboration between ARL, Texas A\&M, and the University of Texas that evaluates digital libraries from the users' perspective. It has been supported to-date with funding from the National Science Foundation's National Science Digital Library program (NSDL). NSDL was created in 2000 to encourage innovations in teaching, research, and learning at all levels of science, technology, engineering, and mathematics.

DigiQUAL represents a modification of the LibQUAL+ ${ }^{\circledR}$ protocol and employs five questions selected randomly from a possible 180 queries. In its initial implementation, DigiQUAL evaluated the services, functionality, and content of the Digital Library for Earth System Education (DLESE), the Computational Science Education Reference Desk (CSERD), Utopia, The Math Forum@Drexel, and the Multimedia Educational Resource for Learning and Online Testing. ${ }^{22}$

\section{MINES for Libraries ${ }^{T M}$}

MINES, developed by the authors, is a web-based transactional survey that collects data on users' demographics and their purpose of use. It is typically administered in real time 
over the course of a year using a random moments sampling plan. MINES has been administered at 40 North American libraries in the last four years. More than 100,000 networked services uses have been surveyed using a standard protocol at those 40 universities since 2003.

Between 2003 and 2005, networked services users at 33 North American libraries were asked to identify their location, status, and purpose of use through the MINES protocol. At main libraries in the United States, for example, $64 \%$ of the 25,698 uses surveyed were by remote users (i.e., not inside the library). This percentage was even higher for the 31,883 academic health sciences library uses surveyed (79\%) and roughly the same for the 20,300 uses surveyed at the Ontario Council of University Libraries (OCUL), where $80 \%$ of their uses were by remote users. ${ }^{23}$

It is important for library service development to note that although the usage of electronic resources is high from outside the library, there is also considerable undergraduate usage of electronic resources from within the main academic library. Many students are coming into the library not just to do email or to access non-academic web sites; many also come to search for e-journal articles and other digital content offered by their libraries.

Analyzing location by status of user at main libraries in the United States, it was determined that the highest digital resources usage from inside the library was by undergraduates (43\%), while on-campus, but not in the library, the largest user group was 
graduate students (40\% of total use), followed by faculty and staff (31\%) and then undergraduate students $(25 \%) .^{24}$

Overall, coursework was the most common purpose of use (42\%) among the nineteen OCUL libraries, followed by sponsored research (26\%) and non-sponsored research $(16 \%){ }^{25}$ The fact that slightly more than one quarter of all usage supported funded research lent considerable support to OCUL's appeal to its provincial government to continue funding its Scholar's Portal initiative because funded researchers relied on its offerings to successfully compete for and carry out important research initiatives.

Overall use among the approximately 26,000 main campus library users surveyed in the United States was predominantly for instruction/coursework/unfunded research (62\%) while funded research usage was approximately $11 \%$ of total use. Networked services use for instruction/coursework/unfunded research did not vary significantly by location (66\% in the library, $63 \%$ on-campus, but not in the library, and $58 \%$ off-campus). The fact that $11 \%$ of networked services use was for sponsored research purposes is significant. Using MINES, cost and use data can be enriched by adding purpose of use data to assign a monetary value for the amount of an academic library's networked services expenses that support funded research.

At main libraries in the United States, usage related to funded research varied more significantly by location, ranging from $21 \%$ on-campus, but not in the library to about $5 \%$ in the library and $6 \%$ off campus. At these main libraries, $72 \%$ of electronic services use 
supporting funded research occurred outside the library, but $83 \%$ of this funded researchrelated remote use took place on campus. At U.S. medical libraries $83 \%$ of electronic services use supporting funded research occurred outside the library, but $92 \%$ of the funded research-related remote use took place on (rather than off) campus. ${ }^{26}$

Recently, several implementations of MINES for Libraries ${ }^{\mathrm{TM}}$ have made significant advances in addressing the problem of capturing all electronic services users, not just those accessing digital content through the library's web pages. The first instance is an advanced application of EZproxy to present the MINES survey instrument to networked services users as they initiate a session. This development is noteworthy because it can be implemented by any library running EZproxy, and because it captures almost all of the networked services usage both locally and remotely during the sampled time periods.

EZproxy is authored by Chris Zagar, systems librarian at Estrella Mountain Community College, one of Arizona's Maricopa Community Colleges. As its Useful Utilities homepage ${ }^{27}$ states, "Since 1999, EZproxy has provided the easiest way for libraries to extend web-based licensed databases to their remote users." EZproxy has subsequently been adopted by 1800 libraries in 46 countries since its introduction in 1999. In June, 2006, Chris Zagar was recognized with the Library and Information Technology Association/Brett Butler Entrepreneurship Award for developing an innovative product (EZproxy) designed to meet the needs of the library world.

As implemented at the University of Texas Medical Branch at Galveston (UTMB) in 2007, the auto-login banner shown to the patron by EZproxy at the first patron login is 
redirected to the MINES survey at the appropriate (i.e., survey sample) times, using EZproxy $4.0 \mathrm{~g}$ (beta). The patron completes the survey, and then is returned to the EZproxy login screen. Because there is a time out period with EZproxy in which a login is not required, this method redirects the first URL access for proxied users, but not subsequent accesses by the same browser.

Don Brunder, Associate Director of Academic Computing, and his staff at UTMB took this methodology and added a line to the ezproxy.cfg to log all uses of the starting point URLs. These data are extracted from the log file through SQL. The end result is that all uses of networked electronic resources that pass through the EZProxy server, whether there is a login or not, are surveyed during the sampled time period. The timeout in the EZproxy cookie resets the survey, when the patron is asked to log in again. This methodology is significant because of its potentially wide applicability; it can be implemented by any library running EZproxy and it captures virtually all of the networked services usage during the sampled time periods. Further work on this approach is in progress.

Another solution to the problems of bookmarks and other non-surveyed usage in point of use surveys is to capture all usage of networked electronic resources at the campus Internet router. Jim Madden, Manager of Network Operations at the University of California, San Diego (UCSD), in collaboration with Steven Wieda, the UCSD Libraries' Web Managing Editor, and a team of information technology specialists at the UCSD Libraries developed an approach which picks up both on-campus users and off-campus 
users who come through the proxy server or virtual private network (VPN). This methodology captures all of the usage of networked electronic resources by authorized users during the randomly selected survey periods since it is administered at the router. It is an excellent example of cooperation between the campus network administrators and the library. The methodology will be explained by the UCSD team in a forthcoming publication.

\section{Conclusion}

Less than a decade into its development, measuring the value and impact of digital content already provides librarians with more useful and accurate data related to collections use than was possible in the print library environment. Measuring digital content use has evolved rapidly since 1999 to encompass initiatives to standardize counting of digital content use, compute unit cost data to reinforce the economic benefits of moving from print to electronic content, calculate local cost benefit analyses for specific titles and packages, gauge user satisfaction with digital content and digital libraries, and mine digital content usage to ascertain users' demographics, location, and purpose of use.

Recent refinement of web-based survey techniques promises to provide librarians with even more representative and reliable samples of digital content use. Web-based surveys can be used to measure user satisfaction and digital library usage that is not vendorsupplied, such as locally mounted digital collections and services and locally hosted open access journals. Surveying at the campus router level or at the proxy re-writer provides a 
comprehensive sampling plan that is able to survey all electronic services users, regardless of their point of entry.

These assessment efforts allow librarians to better understand digital content usage, make more informed collection development decisions and to better justify collections management choices. Librarians are now able to more accurately determine who is using specific digital content. Knowing the locations where networked services are being used (e.g., the majority of faculty prefer to work on-campus, but not in the library) enables librarians to plan user support services accordingly. Determining purpose of use permits academic librarians to identify which electronic resources contribute most to their institutions' primary missions of instruction/education/unfunded research; funded research; patient care; public service; and other institutional activities.

A decade into the electronic information environment, librarians are already far ahead of what they knew about print collections use. In the coming years, there will be further developments in web survey techniques, further progress in the standardization, harvesting, and analysis of vendor-supplied and locally collected digital content usage data, and greater reliability and refinement of the digital content usage data that librarians will increasingly use for assessment, purchasing, and service decisions.

\footnotetext{
${ }^{1}$ Galvin, Thomas and Allen Kent, "Use of a University Library Collection.” Library Journal_102.20 (1977): 2317-2320.

${ }^{2}$ Luther, Judy, Linda Bills, Amy McColl, Norm Medeiros, Amy Morrison, Eric Pumroy, and Peggy Seiden. Library Buildings and the Buildingof a Collaborative Research Collection at the Tri-College Library Consortium: Report to the Andrew W. Mellon Foundation. Washington, D.C.: Council on Library and Information Resources, 2003.

${ }^{3}$ Shepherd, Peter and Denise Davis, "Electronic Metrics, Performance Measures, and Statistics for Publishers and Libraries: Building Common Ground and Standards." portal: Libraries and the Academy 2.4 (2002):659-663.
} 


\footnotetext{
${ }^{4}$ Shim, Wonsik and Charles McClure, "Data Needs and Use of Electronic Resources at Academic Research Libraries." portal: Libraries and the Academy 2.2 (2002):217-236.

${ }^{5}$ Miller, Rush and Sherrie Schmidt. "E-metrics: measures for electronic resources." in Proceedings of the $4^{\text {th }}$ Northumbria International Conference on Performance Measurement in Libraries and Information Services, ed. Joan Stein, Martha Kyrillidou, and Denise Davis, 37-42 (Washington, D.C.:(Association of Research Libraries 2002).

${ }^{6}$ Blixrud, Jullia C. "Measures for Electronic Use: The ARL E-Metrics Project." Paper presented at Statistics in Practice - Measuring and Managing. IFLA pre-conference, Northumbria Lite, 2002.

${ }^{7} \mathrm{http} / / / \mathrm{www}$. arl.org/stats/annualsurveys/sup/index.shtml

${ }^{8}$ Stemper, James A. and Janice M. Jaguszewski, "Usage Statistics for Electronic Journals: An Analysis of Local and Vendor Counts." Collection Management 28.4. (2003) 3-22

${ }^{9} \mathrm{http} / / /$ www.niso.org/committees/SUSHI/SUSHI_comm.html

${ }^{10}$ Luther, Judy, White Paper on Electronic Journal Usage Statistics Washington, D.C.: Council on Library and Information Resources (2000).

${ }^{11}$ White, Andrew and Eric Djiva Kamal E-Metrics for Library and Information Professionals: How to Use Data for Managing and Evaluating Electronic Resources Collections. New York: Neal Schuman (2006)

${ }^{12}$ Stemper, James A. and Janice M. Jaguszewski. "Usage Statistics for Electronic Journals: An Analysis of Local and Vendor Counts," Collection Management 28.4 (2003) 3-22

${ }^{13}$ Caswell, Jerry V. "A Conceptual Framework for Gateways." Information Technology and Libraries 23.2.(2004) 73-82

${ }^{14}$ Galvin and Kent, "Use of a University Library Collection." p. 2317

${ }^{15}$ Franklin, Brinley. "Managing the Electronic Collection with Cost per Use Data" IFLA Journal 31.3. (2005) 241-248

${ }^{16}$ Montgomery, Carol Hanson and Donald W. King. "Comparing Library and User Related Costs of Print and Electronic Journal Collections: A First Step Towards a Comprehensive Analysis" D-Lib Magazine 8.10 (2002)

${ }^{17}$ Obst, Oliver. Patterns and Cost of Printed and Online Journal Usage" Health Information and Libraries Journal 20 (2003) 22-32

${ }^{18}$ Schonfeld, Roger C., Donald W. King, Ann Okerson, and Eileen Gifford Fenton. The Nonsubscription Side of Periodicals: Changes in Library Operations and Costs Between Print and Electronic Formats.

Washington, D.C.:Council on Library and Information Resources (2004)

${ }^{19}$ Galvin and Kent, "Use of a University Library Collection." p. 2317

${ }^{20}$ Samson, Sue, Sebastian Derry, and Holly Eggleston. "Networked Resources, Assessment and Collection Development" The Journal of Academic Librarianship 30.6 (2004) 476-481

${ }^{21}$ Thompson, Bruce, Colleen Cook, and Martha Kyrillidou. Library Users' Service Desires and Tolerances: A LibQUAL+®Study. 2007. preprint.

${ }^{22}$ Kyrillidou, Martha, and Sarah Giersch. "Developing the DigiQUAL Protocol for Digital Library Evaluation." Paper presented at MERLOT International Conference, Nashville, TN, 2005.

${ }^{23}$ Franklin, Brinley and Terry Plum. "Successful Web Survey Methodologies for Measuring the Impact of Networked Electronic Services (MINES for Libraries)" IFLA Journal 32.1 (2006) 28-40

${ }^{24}$ Ibid.

${ }^{25}$ Ibid.

${ }^{26}$ Ibid.

${ }^{27}$ www.usefulutilities.com/
} 